\title{
Culture versus direct specimen test: comparative study of infections with Chlamydia trachomatis in Viennese prostitutes
}

\author{
ANGELIKA STARY,* W KOPP,† W GEBHART, ‡ AND J SÖLTZ-SZÖTS* \\ From the *Ludwig Boltzmann Institut, the + Public Health Centre, and the $\neq$ Department of \\ Dermatology II, University of Vienna, Vienna, Austria
}

SUMMARY To evaluate the sensitivity and specificity of the direct specimen test with monoclonal antibody conjugated with fluorescein isothiocyanate (FITC), cervical smears from 700 Viennese prostitutes were investigated by immunofluorescence microscopy and compared with the results of cultures for Chlamydia trachomatis in McCoy cells. Inclusion bodies in cell culture and elementary bodies on the smear slide were counted and evaluated in four categories. Cultures were obtained from $12 \cdot 6 \%(88)$ of all women investigated, whereas the direct specimen test gave positive results in $10.4 \%(73)$.

The results indicate that in asymptomatic people with only few inclusion bodies and latent infections, culture on McCoy cells is the more adequate method of identifying Chlamydia trachomatis.

\section{Introduction}

Infections with Chlamydia trachomatis have gained increasing importance in the range of sexually transmitted disease (STD) all over the world. Reliable and rapid diagnosis has therefore become urgently needed to control the sometimes severe complications of non-gonococcal urethritis (NGU) or cervicitis caused by these organisms.

Information has accumulated about the association of chlamydial infection and pelvic inflammatory disease (PID). ${ }^{1-3}$ Treharne et al claim that two thirds of all cases of acute salpingitis have chlamydial aetiology. ${ }^{4}$ Chlamydiae may also be responsible for some cases of spontaneous abortion. ${ }^{5}$ Complications of chlamydial infection in men include acute upethroprostatitis and epididymitis, and in women chlamydiae may be the most important cause of infertility. In women with chlamydial infection the fertility prognosis is worse than in those from whom gonococci are recovered. ${ }^{6}$ Animal studies ${ }^{7}$ and clinical reports on affected neonates ${ }^{8}$ support the assumption that $C$ trachomatis is the causative agent

Address for reprints: Dr Angelika Stary, Ludwig Boltzmann Institut, 1090 Wien, Spitalgasse 2, Austria

Accepted for publication 19 November 1984 in a proportion of cases of pneumonia in human infants, having been transmitted from the genital tracts of their mothers.

In recent years a rapid diagnostic test using monoclonal antibodies labelled with fluorescein isothiocyanate (FITC) has become available in addition to the well established tissue culture technique. The reagent identifies specifically the major outer membrane protein (MOMP) of $C$ trachomatis, and the antibodies detect all 15 serological types of the organism. The sensitivity and specificity of the direct test has been reported as being very high in patients attending an STD clinic. ${ }^{9}$

The aim of the investigation reported here was to examine the specificity and sensitivity of the rapid smear slide test in asymptomatic people, to compare it with the results of chlamydial cultures, and to correlate both methods by counting the elementary bodies and inclusion bodies on each slide.

\section{Patients and methods}

We studied 700 prostitutes who attended the public health centre in Vienna for weekly STD screening in January and February 1984. Cervical swabs for chlamydial investigation were taken by the medical staff using standardised techniques. Each swab was first rolled on a slide to produce a smear specimen 
and then placed in 2SP (sucrose phosphate) medium with $2 \%$ fetal calf serum and refrigerated until further investigated.

The slides were fixed using cooled acetone, and were incubated for 30 minutes at room temperature with one drop of the undiluted FITC conjugated commercially available monoclonal antibody (Syva Company, Palo Alto, San Francisco, USA). After being rinsed in phosphate buffered saline (PBS) and dried, the specimens were mounted and examined in a Reichert fluorescence microscope at room temperature. Chlamydia positive specimens contained apple green elementary bodies.

Cultures were performed in McCoy cells treated with cycloheximide for $\mathbf{4 8}$ hours and then stained by an FITC conjugated monoclonal antibody (Syva). ${ }^{9}$ Infected cells could be identified by the presence of brightly glowing, apple green inclusion bodies.

In both slides and cultures, the elementary and inclusion bodies were counted. The results were categorised as follows: category 1: negative (no elementary or inclusion bodies); category 2 : (up to 10 elementary or inclusion bodies); category $3:$ (10 to 100 elementary or inclusion bodies); category 4 : (more than 100 elementary or inclusion bodies).

The data were analysed by the SPSS computer program on a CDC (Cyber 710) computer at the University of Vienna; tests of significance were performed by the "crosstabs" procedure.

\section{Results}

DIRECT SPECIMEN TEST

Table I shows that elementary bodies were found in $73(10.4 \%)$ of the 700 prostitutes. Of the 73 positive smears, $46(63 \%)$ contained fewer than 10 elementary bodies and were thus classified as category 2,23 $(31 \cdot 5 \%)$ were in category 3 , but only four $(5 \cdot 5 \%)$ were in category 4 .

TABLE I Results of direct specimen tests from 700 prostitutes

\begin{tabular}{lrc}
\hline Results & \multicolumn{2}{c}{ No $(\%)$ of patients } \\
\hline Negative & 627 & $(89 \cdot 5)$ \\
Positive: & 46 & $(6 \cdot 6)$ \\
$<10$ elementary bodies & 23 & $(3 \cdot 3)$ \\
$\quad 10-100$ elementary bodies & 4 & $(0 \cdot 6)$ \\
$\quad 100$ elementary bodies & 73 & $(10 \cdot 5)$ \\
Subtotal & 700 & $(100 \cdot 0)$ \\
Total & & \\
\hline
\end{tabular}

CULTURE

Table II shows that positive cultures were found in 88 $(12 \cdot 6 \%)$ prostitutes. Of the positive cultures, 38 $(43 \cdot 2 \%)$ contained fewer than 10 inclusion bodies (category 2$)$, whereas $30(34 \cdot 1 \%)$ were classified as category 3 and $20(22 \cdot 7 \%)$ as category 4 .
TABLE II Results of cultures from 700 prostitutes

\begin{tabular}{lrc}
\hline Results & \multicolumn{2}{c}{ No (\%) of patients } \\
\hline Negative & 612 & $(87 \cdot 4)$ \\
Positive: & 38 & $(5 \cdot 4)$ \\
$<10$ inclusion bodies & 30 & $(4 \cdot 3)$ \\
$\quad 10-100$ inclusion bodies & 20 & $(2 \cdot 9)$ \\
$>100$ inclusion bodies & 88 & $(12 \cdot 6)$ \\
Subtotal & 700 & $(100 \cdot 0)$ \\
Total & \\
\hline
\end{tabular}

SPECIFICITY AND SENSITIVITY

Table III shows that of the 612 prostitutes yielding negative cultures, $605(98 \cdot 9 \%)$ were negative and seven $(1 \cdot 1 \%)$ positive in the direct test, which indicated that the specificity of the direct specimen test was about $99 \%$. Of the 88 who yielded positive cultures, $66(75 \%)$ gave positive results and $22(25 \%)$ negative results on direct testing. The sensitivity of the direct specimen test was therefore calculated as being $75 \%$ in our study population.

TABLE III Specificity and sensitivity* of direct specimen tests in 700 prostitutes

\begin{tabular}{lll}
\hline & \multicolumn{2}{l}{ No (\%) of cultures: } \\
\cline { 2 - 3 } $\begin{array}{l}\text { Results of direct } \\
\text { specimen tests }\end{array}$ & $\begin{array}{l}\text { Negative } \\
(n=612)\end{array}$ & $\begin{array}{l}\text { Positive } \\
(n=88)\end{array}$ \\
\hline $\begin{array}{l}\text { Negative }(\mathrm{n}=627) \\
\text { Positive }(\mathrm{n}=73)\end{array}$ & $605(98 \cdot 9)$ & $22(25)$ \\
\hline
\end{tabular}

*According to cross tabulation, direct specimen test was $99 \%$ specific and $75 \%$ sensitive.

ANALYSIS OF RESULTS OF BOTH METHODS Table IV shows a correlation between the results of culture and direct examination in $636(90.9 \%)$ specimens. Of 612 in category 1 (negative) on culture, $605(98.9 \%)$ were also negative on direct examination and the remaining seven $(1 \cdot 1 \%)$ were in category 2 (containing $<10$ elementary bodies) on direct examination. Of 38 specimens in category 2 (containing $<10$ inclusion bodies) on culture, 22 $(57.9 \%)$ were in the same category on direct examination, $15(39.5 \%)$ in category 1 , and one

TABLE IV Cross tabulation of results of culture and direct specimen tests in 700 prostitutes

\begin{tabular}{llllll}
\hline & \multicolumn{4}{l}{ No (\%) vielding cultures in category** } \\
\cline { 2 - 5 } $\begin{array}{l}\text { Results of direct } \\
\text { specimen tests }\end{array}$ & $I(n=612)$ & $2(n=38)$ & $3(n=30)$ & $4(n=20)$ \\
\hline Category*: & & & & \\
$1(n=627)$ & $605(98 \cdot 9)$ & $15(39 \cdot 5)$ & $6(20)$ & 1 & $(5)$ \\
$2(n=46)$ & $7(1 \cdot 1)$ & $22(57 \cdot 9)$ & $13(43 \cdot 3)$ & $4(20)$ \\
$3(n=23)$ & 0 & 1 & $(2 \cdot 6)$ & $8(26 \cdot 7)$ & $14(70)$ \\
$4(n=4)$ & 0 & 0 & $3(10)$ & $1(5)$ \\
\hline
\end{tabular}

*No of inclusion bodies seen on culture or elementary bodies in direct specimens as follows: category $1=0$ (negative), category $2=$ $<10$, category $3=10-100$, category $4=>100$. 
$(2 \cdot 6 \%)$ in category 3 (containing 10-100 elementary bodies) on direct examination. Of 30 specimens in category 3 (10-100 inclusion bodies) on culture, only eight $(26.7 \%)$ were in the same category on direct examination, $13(43.3 \%)$ were in category 2 , six $(20 \%)$ in category 1 , and three $(10 \%)$ in category 4 (containing $>100$ elementary bodies) on direct examination. Of the remaining 20 specimens that were in category 4 (containing $>100$ inclusion bodies) on culture, only one $(5 \%)$ was in the same category on direct examination. $14(70 \%)$ were in category 3 , four $(20 \%)$ in category 2 , and one $(15 \%)$ in category 1 on direct examination.

\section{Discussion}

Over the past few years several workers have reported attempts to analyse infections with $C$ trachomatis, especially to correlate the demonstration of organisms with symptoms and severity of the disease. ${ }^{10}$ Most agreed that large numbers of inclusions were present more often in men than in women patients. ${ }^{11} 12$ In addition, correlation between the numbers of inclusion bodies and the presence of mucopurulent secretions and cervical ectopia could be demonstrated. ${ }^{10} \mathrm{~A}$ comparative study of different groups of women showed a noticeably smaller number of inclusion bodies in prostitutes compared with patients attending sexually transmitted disease clinics. ${ }^{12}$

The report on Viennese prostitutes published here also showed a high percentage of infections with relatively few organisms, as only $20(22 \cdot 7 \%)$ out of 88 positive samples contained more than 100 inclusion bodies. This phenomenon could be explained by the fact that the weekly compulsory examinations of Viennese prostitutes and common self medication favour the emergence of latent or asymptomatic infections in this group.

The incidence of chlamydial infections in Viennese prostitutes decreased from $20.4 \%$ in 1980 to $12.6 \%$ in 1984 (Kopp, Stary, Gebhart, Söltz-Szöts, unpublished observation). ${ }^{13}$ We think that this decrease in morbidity can be ascribed to greater patient awareness and more efficient treatment of infection.

Several recent efforts have been aimed at simplifying the diagnostic procedures for chlamydial infections to facilitate more efficient screening of larger populations and to reduce complications of the disease. The development of a direct specimen test using monoclonal antibodies seems to be a promising step in this direction. In 1984 Stamm et al noted an excellent correlation between the results of culture and those of smear microscopy, the specificity being 96-99\% and the sensitivity approaching 86-92\%.9
Handsfield et al presented a study of a population with low prevalence of chlamydial infection, and reported a specificity of $99 \%$ and a sensitivity of $83 \%$ (Handsfield, Jasman, Kothenbeutel, Roberts, Stamm, unpublished observation).

From our results we conclude that both direct specimen test and culture seem to be almost equally specific (Stary, Kopp, Gebhart, Sölz-Szöts, unpublished observation). Culture, however, is more sensitive if only few elementary bodies are present in the exudate. We found false negative results to the direct specimen test in up to $40 \%$ of our samples that contained fewer than 10 inclusion bodies on culture. In asymptomatic people, therefore, culture appears to be the most adequate diagnostic technique. In most patients suffering from chlamydia induced inflammatory symptoms, however, a large number of elementary bodies can be expected. The advantages of lower costs, more rapid and simplified handling, and high specificity, make the direct specimen test a considerable advance in the screening of large groups for chlamydial infections.

We thank Mrs L Aster and Mag R Maly for their excellent technical help in collecting and processing the specimens.

\section{References}

1. Sweet RL. Pelvic inflammatory disease: etiology, diagnosis, and treatment. Sex Transm Dis 1981;8:308-15.

2. Dalaker K, Gjonnaess H, Kvile G, Urnes A, Anestad G, Bergan T. Chlamydia trachomatis as a cause of acute perihepatitis associated with pelvic infammatory disease. British Journal of Venereal Diseases 1981;57:41-3.

3. Paavonen J, Valtonen VV. Chlamydia trachomatis as a possible cause of peritonitis and perihepatitis in a young women. British Journal of Venereal Diseases 1980; 56:341-3.

4. Treharne JD, Ripa KT, Mårdh P-A, Svensson L, Weström L, Darougar S. Antibodies to Chlamydia trachomatis in acute salpingitis. British Journal of Venereal Diseases 1979;55:26-9.

5. Stor J. Chlamydia and chlamydia-induced diseases. Springfield, Illinois: Thomas, 1971.

6. Weström $\mathrm{L}$. Effect of acute pelvic inflammatory disease on fertility. Am J Obstet Gynecol 1975; 121:707-13.

7. Harrison HR, Alexander ER, Chiang W-T, et al. Experimental nasopharyngitis and pneumonia caused by Chlamydia trachomatis in infant baboons: histopathologic comparison with a case in a human infant. $J$ Infect Dis 1979; 139: 141-6.

8. Arth C, von Schmidt B, Grossmann M, Schachter J. Chlamydial pneumonitis. J Pediatr 1978; 93:447-9.

9. Stamm WE, Harrison HR, Alexander ER, et al. Diagnosis of $C$ trachomatis infections by direct immunfluorescence staining of genital secretions. A multicenter trial. Ann Intern Med 1984; 101:638-41.

10. Hobson D, Karayiannis P, Byng RE, Rees E, Tait IA, Davies J. Quantitative aspects of chlamydial infection of the cervix. British Journal of Venereal Diseases 1980;56:156-62.

11. Mallison H, Arya OP, Goddard AD. Quantitative study of Chlamydia trachomatis in genital infection. British .Journal of Venereal Diseases 1982;58:36-9.

12. Mösinger-Lundgren V, Hofmann $H$, Petzold D. Die Häufigkeit genitaler Chlamydien-und Mykoplasmeninfektionen bei Frauen. Z Hautkr 1984;59:43-7.

13. Stary A, Gebhart W, Gross W, Kopp W, Söltz-Szöts J, Thurner J. Genitale Chlamydieninfektionen bei STD ( = sexually transmitted diseases) Risikopatientinnen. Wien Klin Wochenschr 1982; 94:484-7. 